\title{
Dreidimensionale Einblicke für sichere Diagnostik
}

Mit dem VistaVox S präsentieren Dürr Dental auf den Herbstmessen 2016 eine Innovation, die Implantologen, Oralchirurgen und Allgemeinzahnärzten neben DVT-Aufnahmen auch OPGs in perfekter Bildqualität liefert. Das Fieldof-View des Volumentomografen ist mit einem kieferförmigen Ø 100 $\mathrm{x} 85 \mathrm{~mm}$ so angelegt, dass der vollständige Bereich bis zu den hinteren Molaren sicher abgebildet wird. Dies bietet mit einer einzigen Positionierung die Voraussetzun-

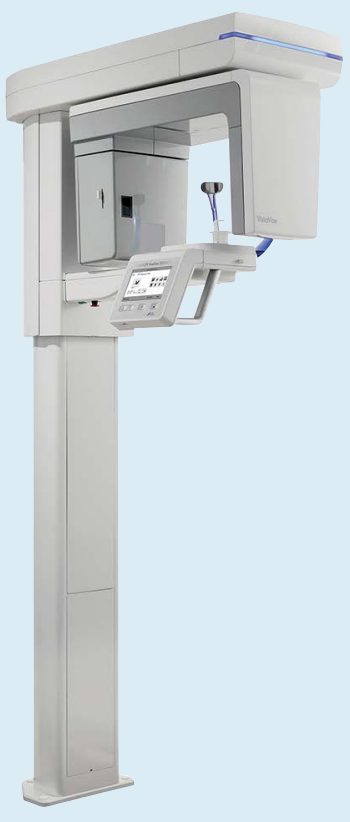
gen für nahezu jeden 3D-Befund im dentalen Bereich. Durch die anatomisch angepasste Volumenform wird ein diagnostischer Bereich abgedeckt, der mit konventioneller 3D-Technik teure Geräte eines Volumens mit $130 \mathrm{~mm}$ Durchmesser erfordern würde. Ergänzt durch die 17 Panoramaprogramme in bewährter S-Pan-Technologie, sind Zahnarztpraxen sowohl im 2D-als auch im 3D-Bereich mit bester bildgebender Diagnostik ausgestattet. Das Alleinstellungsmerkmal von VistaVox $S$ liegt in seinem 3D-Abbildungsvolumen, das sich an der menschlichen Anatomie orientiert. Zusätzlich trägt der hochempfindliche CsI-Sensor zur Reduktion der Strahlenexposition bei, was durch eine schlanke Sensorgeometrie und ausgeklügelte Kinematik erreicht wird.

Nach einer Pressemitteilung der

Dürr Dental AG, Bietigheim-Bissingen

www.duerrdental.com 